\title{
PSYCHOSOCIAL FACTORS AS RISK FACTOR IN SUICIDAL POISONING: A CROSS-SECTIONAL STUDY
}

\author{
ASAWARI RAUT*, KAVYA SHAJ, ATMARAM PAWAR \\ Department of Clinical Pharmacy, Poona College of Pharmacy, Bharati Vidyapeeth Deemed University, Pune, Maharashtra, India. \\ Email: pharmasawari1@gmail.com
}

Received: 07 April 2017, Revised and Accepted: 12 May 2017

\begin{abstract}
Objective: Suicide is known to be a phenomenon in low-, middle-, and high-income countries and occurs in all sociodemographic groups. It ranges from acute to fatal lethal attempts which occur in the context of a social crisis. Deliberate self-poisoning for suicide is a growing public health concern with frequent emergency department admissions. An epidemiological surveillance is essential for every region to understand the pattern, underlying psychological factors, and the scope of preventive measures.
\end{abstract}

Methods: The 2-year retrospective study describes the epidemiology and influencing factors of suicides by self-poisoning in patients admitted to a Government Hospital and a Teaching Hospital in Pune, Maharashtra, from January 1, 2014 to December 31, 2015.

Result: Out of 1010 poisoning cases reported, 539 were suicidal self-poisoning. Significantly males more than females were brought to the hospitals due to deliberate self-poisoning $\left(1: 0.86, \chi^{2}=38.05 ; \mathrm{p}<0.001\right)$. The age group most recorded was 20-35 years $(67.7 \%)$. Psychosocial factors were associated with increased risk of suicidal self-poisoning attempts (risk ratio 4.76, 95\% confidence interval 4.07-5.57; p<0.001). Psychosocial factors were interpersonal conflict (52.4\%), stress (30.4), dissatisfaction in life (6\%), and alcoholism or mental disorders (11.1\%). Household and agricultural products (71.8\%) were the popular choices of the toxic agent in self-poisoning with phenols (20\%) being the most common. 19 cases (3.5\%) were severe, out of which 15 cases lead to death (2.8\% mortality).

Conclusion: There is an urgent need to develop and implement preventative and treatment strategies for high-risk groups attempting suicide by self-poisoning.

Keywords: Suicide, Self-poisoning, Psychosocial factors, Deliberate self-harm.

(C) 2017 The Authors. Published by Innovare Academic Sciences Pvt Ltd. This is an open access article under the CC BY license (http://creativecommons. org/licenses/by/4. 0/) DOI: http://dx.doi.org/10.22159/ajpcr.2017.v10i8.18983

\section{INTRODUCTION}

Deliberate self-harm (DSH) or suicide is an impulsive response to emotional misbalance, wherein the victim experiencing the state believes in self-destruction as a solution to the problems faced. Over 800,000 people die due to suicide every year, and there are many more who attempt suicide. Hence, many millions of people are affected or experience suicide bereavement every year. Suicide occurs throughout the life span and was the second leading cause of death among 15-29 years old globally in 2012. Suicide is a global phenomenon in all regions of the world; in fact, $75 \%$ of global suicide occurred in low- and middle-income countries in 2012 . Suicide accounted for $1.4 \%$ of all deaths worldwide, making it the $15^{\text {th }}$ leading cause of death [1]. Deliberate self-poisoning is the leading method of attempted suicide and has lead to increased emergency department admissions. Individuals who have inflicted harm can be categorized as ones with failed attempt who wanted to die and others with non-fatal intentions to draw attention or threaten.

The pattern of self-poisoning is influenced by various factors. First, the choice of poison wherein in industrialized countries, drug overdose is used for most self-poisoning, whereas in developing countries, agricultural pesticides and household agents. Second, the ease of availability of poison as most of the rural population is involved in agriculture, and pesticides are readily available in the house. Furthermore, the urban population has access to household insecticides, cleaning agents, and medications [2-5] and finally, the socioeconomic status. The high cost of hospitalization and advanced medical care is not affordable and available to everyone, and during a self-poisoning crisis, choosing cheaper options at times result in severe complications.
Moreover, in developing countries, the epidemiological records of these attempts are unavailable or distorted. Different age and gender patterns of self-harm available possibly explain that young adults particularly are more likely to take impulsive measures, and as these are unplanned, agents used are which readily available. In China and Sri Lanka, some of the highest rates are seen in young adults with a varied male:female ratio.

Possible strategies to reduce this need detailed epidemiological data of risk population, circumstances, and toxic substances. Currently, in India, lack of updated information, a few established poison centers and limited national surveillance have become a hurdle in implementing prevention and targeted intervention programs. This study characterizes poisoning with regard to demographic factors (i.e., age, sex, and residence), common toxic agents used, and their case fatality rates as well as the overall mortality rate of self-poisoning in Pune.

Pune is a district in the state of Maharashtra in India. According to the most recent census in 2011, the total population was 9.4 million making it the fourth most populous district in India. Known as the Oxford of the East with prestigious academic and research institutions attracts a young crowd. The agricultural diversity along with its rapidly expanding industrial hub has provided easy accessibility to harmful chemicals.

\section{METHODS}

Study area

The study was conducted in Pune district of Maharashtra, which resides a total population of 9.4 million inhabitants with a male:female ratio of 
1.1:1. It forms a part of the tropical monsoon land and therefore shows a significant seasonal variation in temperature and rainfall.

The Pune city resides many multispecialty hospitals. The government hospital, a 380-bedded multispecialty hospital, is located in Pimpri - Chinchwad which engulfs a wide area of surrounding suburban and industrial areas such as Aundh, Bhosari, Nigdi, and villages such as Moshi, Chikhali, and Dehu. The private teaching hospital is a 900-bedded hospital with hi-tech super specialties. It is located in inner suburbs of Pune which includes areas such as Katraj, Ambegaon, Vadgaon, and Parvati Hill. These are the industrial and agricultural areas where a high number of chemical or pesticide poisoning can be observed.

\section{Population and sampling}

The study was cross-sectional and made use of retrospective extraction of data from records available at the government and private teaching hospitals, respectively. All cases of poisoning available in the medical record departments were included in the study.

\section{Data collection and extraction}

The records were collected from the Medical Record Department of the respective hospitals. The data collection period was from January 2014 to December 2015. The cases were reviewed for gender, age, route and reason of poisoning, seasonal variation, and agents. Poisonous agents were described and grouped in accordance with the International Statistical Classification of Diseases and Related Health Problems $10^{\text {th }}$ Revision.

\section{Statistical analysis}

Data were collected in predefined forms. Chi-square test was used to determine the association between the variables. $p<0.05$ was used to determine significance. The relative risk or risk ratio (RR), its standard error, and 95\% confidence interval are calculated according to Altman, 1991.

\section{RESULTS AND DISCUSSION}

In 2 years, the total numbers of cases of intentional poisoning reported were 539. Marital status and occupational background were not included in the study due to inappropriateness and unavailability of data in many case files. The sex, age, reason of poisoning, route of poisoning, seasonal variation, and agents involved in poisoning are according to the records available.

The results from this study revealed that most of the cases reported to the emergency department for suicide attempt by self-poisoning were males, a finding that is contrary to the previous studies where female outnumbered male [6-10]. The male:female ratio was 1:0.86 and significant $(\mathrm{p}<0.01)$. The finding consistent with the literature is that most of the cases reported represented persons in the age range 20-35 years (67.7\%) [11] followed by 13-19 years (19.1\%). This supports research that indicates that adolescents and young people are most at risk for suicide attempts [6,7,9]. Moreover, all other age categories showed high self-poisoning tendency in male except in 13-19 age category where female reported nearly twice admissions due to self-harm (Tables 1 and 2).

The patients who self-poisoned had consumed a combination of harmful chemicals and even with mixed alcohol. Household and agricultural agents were maximum consumed $(71.8 \%)$, and this is similar to the findings by other studies performed in India [2,12-14]. Phenol-containing agents reported 108 cases followed by rodenticides, organophosphates and carbamates with 81 and 72 cases, respectively. Kerosene, corrosive acids, alcohol, detergents, organochlorine, and paraquat cases were also seen. Furthermore, drug overdose was also reported with $20.8 \%$ incidence. Sedative hypnotics and psychotropics were used and also certain analgesics, antibiotics, and topical lotions. Most cases had consumed unknown combination of drugs as well. 40 cases of unknown poison consumption were also treated. Agents of poisoning showed a similar trend in all age categories with a maximum consumption of household agents followed by drugs for DSH (Tables 1 and 3).

Nearly $79.5 \%$ of cases were mild and symptoms improved in maximum, i.e., $82.7 \%$ of patients. About $3.5 \%$ of cases were severe, and $2.8 \%$ of mortality reported. Furthermore, $14.5 \%$ of cases absconded or discharged against medical advice. Furthermore, out of the 15 death cases, 14 were male and maximum in the age category of 20-35. Time of hospitalization of these death cases was considerably maximum during $12 \mathrm{pm}$ to $6 \mathrm{pm}$ and highest during the summer season. Agents responsible for death were organophosphates ( 6 cases), organochlorine benzene hexachloride (BHC); BHC (2 cases), BHC with alcohol (4 cases), alcohol ( 2 cases), and alprazolam (1 case) (Tables 1 and 4 ).

The different psychological factors which influenced suicidal tendencies in the admitted poisoning cases were recorded. The reasons were unavailable for few intentional poisoning cases. A clinical impression of psychosocial factors as a risk factor for distal sensory polyneuropathy can be established by calculating RR. RR 4.76 with $95 \%$ confidence interval (CI) 4.0799-5.5721, significance p<0.001, NNT (Harm) 1.265 with $95 \%$ CI 1.331-1.206.

Four main factors were interpersonal conflict, stress, dissatisfaction, and others. Interpersonal conflict was the chief reason and this is consistent with the literature that interpersonal conflict is among the top-stated reasons for suicide attempts, especially among young people [15-17]. The conflicts included fights and arguments with family members, friends, and even colleagues. Most victims stated the reason as domestic dispute and thus a higher ratio of women who involved in these disputes attempted poisoning. In addition, the age group of 20-35 showed maximum poisoning followed by teenagers due to interpersonal conflict. Most of the cases were mild, and choices of agents were mainly household agents followed by drugs. Maximum patients showed improvement in their symptoms, and also 3 death cases were

Table 1: Patient characteristics of deliberate self-harm cases

\begin{tabular}{ll}
\hline Characteristics & $\begin{array}{l}\text { Intentional } \\
\mathbf{N = 5 3 9 ( \% )}\end{array}$ \\
\hline Sex & \\
Male & $289(53.6)$ \\
Female & $250(46.4)$ \\
Age & \\
13-19 & $103(19.1)$ \\
$20-35$ & $365(67.7)$ \\
$36-55$ & $58(10.8)$ \\
$>55$ & $13(2.4)$ \\
Season & \\
Summer & $185(34.3)$ \\
Rainy & $194(36.0)$ \\
Winter & $160(29.7)$ \\
Severity & \\
Mild & $409(75.9)$ \\
Moderate & $111(20.6)$ \\
Severe & $19(3.5)$ \\
Agent involved & \\
Household and agricultural products & $387(71.8)$ \\
Drugs & $112(20.8)$ \\
Unspecified & $40(7.4)$ \\
Outcome & \\
Symptom improved & $446(82.7)$ \\
DAMA & $78(14.5)$ \\
Death & $15(2.8)$ \\
Psychosocial factor & \\
Interpersonal conflict & $217(52.5)$ \\
Stress & $126(30.4)$ \\
Dissatisfaction & $25(6.0)$ \\
Others & $46(11.1)$ \\
\hline DAMA: Discharge against medical advice & \\
&
\end{tabular}


Table 2: Age-wise distribution of DSP cases

\begin{tabular}{|c|c|c|c|c|c|}
\hline \multirow[t]{2}{*}{ Characteristics } & \multicolumn{4}{|l|}{ Age in years } & \multirow[t]{2}{*}{$\mathbf{p}$} \\
\hline & $13-19(\mathrm{~N}=103)$ & $20-35(\mathrm{~N}=365)$ & $36-55(\mathrm{~N}=58)$ & $>55(\mathrm{~N}=13)$ & \\
\hline \multicolumn{6}{|l|}{ Sex } \\
\hline Female & 71 & 163 & 14 & 2 & $<0.01$ \\
\hline \multicolumn{6}{|l|}{ Agent involved } \\
\hline Household and agricultural products & 72 & 262 & 47 & 6 & \multirow{3}{*}{0.22} \\
\hline Drugs & 25 & 75 & 7 & 5 & \\
\hline Unspecified & 6 & 28 & 4 & 2 & \\
\hline \multicolumn{6}{|l|}{ Severity } \\
\hline Mild & 94 & 279 & 34 & 0 & \multirow[t]{3}{*}{$<0.01$} \\
\hline Moderate & 9 & 77 & 20 & 5 & \\
\hline Severe & 0 & 9 & 4 & 8 & \\
\hline \multicolumn{6}{|l|}{ Outcome } \\
\hline Symptom improved & 92 & 300 & 48 & 7 & \multirow[t]{3}{*}{$<0.01$} \\
\hline DAMA & 11 & 59 & 6 & 2 & \\
\hline Death & 0 & 6 & 4 & 4 & \\
\hline
\end{tabular}

DSP: Distal sensory polyneuropathy, DAMA: Discharge against medical advice

Table 3: Classification of poison agents according to ICD-10

\begin{tabular}{lll}
\hline Type of poison & ICD-10 & $\begin{array}{l}\text { Number of } \\
\text { cases }\end{array}$ \\
\hline Organophosphates and carbamates & T60.0 & 72 \\
Other insecticides & T60.2 & 33 \\
Rodenticides & T60.4 & 81 \\
Other pesticides & T60.8,9 & 3 \\
Kerosene & T52.0 & 12 \\
Phenol and related agents & T54.0 & 108 \\
Corrosives acids and alkali & T54.1/2/3/9 & 9 \\
Other organic solvents & T52.8 & 3 \\
Alcohol & T51 & 54 \\
Soap and detergent & T55 & 3 \\
Organochlorine & T53 & 6 \\
Herbicides-paraquat & T60.3 & 12 \\
Antibiotic & T36 & 16 \\
Non-opioid analgesics and antipyretics & T39 & 8 \\
Antiepileptic, sedative hypnotics & T42 & 32 \\
Psychotropic & T43 & 16 \\
Cardiac-stimulant glycoside & T46.0 & 8 \\
Vaccines and unknown medication & T50 & 32 \\
Topical lotion & T49 & 8 \\
\hline
\end{tabular}

ICD: International Statistical Classification of Diseases and Related Health Problems $10^{\text {th }}$ Revision

due to suicide influenced by domestic disputes. Stress was the second highest factor influencing suicides. These patients faced stress due to examinations, tension at home, responsibilities, and burden of loan payment or debt. Dissatisfaction was the other reason with feelings such as disappointment, failed expectations, and loss of hope due to events in personal and professional life leading to self-poisoning. Other factors such as chronic health problems and alcohol influence also influenced psychology of individuals who felt helpless and committed suicide. History of a psychiatric illness was not a predominant characteristic of patients who attempted suicide, and this is an interesting finding as extensive research has shown that a mental disorder is strongly associated with suicidal ideation and attempts $[6,7,9,18]$. However, there is a possibility that this is an underrepresentation as some of these patients may, in fact, have a psychiatric illness that has been undiagnosed up to the point of their ER visit. Overall female and young adults of age 20-35 were reported to be most affected by psychosocial factors (Table 5).

\section{Limitations}

The study was conducted retrospectively, and prospective study should be conducted to observe and manage patient clinically. Proper maintenance of records was not found in the government setting,
Table 4: Patient characteristics of DSH mortality

\begin{tabular}{ll}
\hline Characteristics & Number of cases \\
\cline { 2 - 2 } & Death \\
\hline Sex & \\
Male & 14 \\
Female & 1 \\
Age & \\
$13-19$ & 1 \\
$20-35$ & 6 \\
$36-55$ & 4 \\
$>55$ & 4 \\
TOH & \\
6 am-12 pm & 3 \\
12 pm-6 pm & 8 \\
6 pm-12 am & 5 \\
Season & \\
Summer & 5 \\
Rainy & 6 \\
Winter & 4 \\
Agent involved & \\
OPP & 6 \\
BHC & 6 \\
Alcohol & 4 \\
Alprazolam & 1 \\
\hline
\end{tabular}

DSH: Deliberate self-harm, TOH: Time of hospitalization, BHC: Benzene hexachloride

and multispecialty care was not provided. Some case reports were torn while others were missing. Patient details such as background, marital status, location of stay, and time of exposure were not found in majority case report. Cases referred from other hospitals lacked proper patient history. The time of exposure and admission was not properly recorded.

\section{CONCLUSION}

The findings of this study highlight the trending characteristics of persons who have attempted suicide by self-poisoning. It provides mostly consistent data to those presented by numerous global researchers and indicates a psychosocial pattern as well as for suicide risk factors. The psychosocial influences are a dominant risk factor and can be used to predict and avoid suicidal poisonings. Increased intentional poisoning in teens and adults emphasizes on importance of counseling and awareness about depression and stress affecting the major strata of the society which increases suicidal tendencies [19]. The pattern suggests that if this issue left unattended can be a burden on the health economy. Burden of self-poisoning brought to casualty demands 
Table 5: Patient characteristics of different psychosocial factors

\begin{tabular}{|c|c|c|c|c|}
\hline Characteristics & Interpersonal conflict & Stress & Dissatisfaction & Others \\
\hline \multicolumn{5}{|l|}{ Sex } \\
\hline Male & 81 & 53 & 7 & 23 \\
\hline Female & 136 & 73 & 18 & 23 \\
\hline \multicolumn{5}{|l|}{ Age } \\
\hline $13-19$ & 39 & 7 & 7 & 4 \\
\hline $20-35$ & 150 & 108 & 18 & 18 \\
\hline $36-55$ & 21 & 11 & 0 & 17 \\
\hline \multicolumn{5}{|l|}{ Severity } \\
\hline Mild & 168 & 108 & 14 & 35 \\
\hline Moderate & 42 & 18 & 11 & 11 \\
\hline Severe & 7 & 0 & 0 & 0 \\
\hline \multicolumn{5}{|l|}{ Agent involved } \\
\hline Household and agricultural & 144 & 109 & 14 & 25 \\
\hline Drugs & 66 & 14 & 11 & 17 \\
\hline Unspecified & 7 & 4 & 0 & 4 \\
\hline Symptom improved & 207 & 126 & 25 & 39 \\
\hline DAMA & 7 & 0 & 0 & 7 \\
\hline Death & 5 & 3 & 1 & 2 \\
\hline
\end{tabular}

DAMA: Discharge against medical advice

strategies for identification and rational management providing optimal outcomes.

\section{Future directions}

Very few studies on self-poisoning targeted cases have been done in the country with over 1.2 billion population. More studies focusing on epidemiology should be encouraged in different hospital settings and geographical areas to study the pattern of poisoning, its morbidity, and mortality. A long-term prospective study is needed in case of poisoning for understanding the clinical pattern and management techniques which can help in intervention for a better outcome. An urgent need to implement preventative and intervention strategies to combat suicide needs national emphasis and awareness measures. It should also involve accurate and appropriate assessments of those people at risk.

\section{REFERENCES}

1. WHO Website. Available from: http://www.who.int/mental health/ prevention/suicide/suicideprevent/en/. [Last accessed on 2017 Mar 10].

2. Patil A, Peddawad R, Verma VC, Gandhi H. Profile of acute poisoning cases treated in a tertiary care hospital: A study in Navi Mumbai. Asia Pac J Med Toxicol 2014;3:36-40.

3. Afshari R, Majdzadeh R, Balali-Mood M. Pattern of acute poisonings in Mashhad, Iran 1993-2000. J Toxicol Clin Toxicol 2004;42(7):965-75.

4. Z'gambo J, Siulapwa Y, Michelo C. Pattern of acute poisoning at two urban referral hospitals in Lusaka, Zambia. BMC Emerg Med 2016;16:2

5. Centers for Disease Control and Prevention. Quick Stats: Number of Deaths From Poisoning, Drug Poisoning, and Drug Poisoning Involving Opioid Analgesics - United States; 1999-2010. Available from: https://www.cdc.gov/mmwr/preview/mmwrhtml/mm6212a7. html. [Last accessed on 2017 Mar 26].

6. World Health Organization. The Global Burden of Disease: 2004. Geneva: WHO; 2008.

7. Pan American Health Organization. Suicide Mortality in the Americas:
Regional Report. Washington, DC: PAHO; 2009.

8. World Health Organization. World Health Report 2001: Mental Health, New Understanding, New Hope. Geneva: WHO; 2001.

9. Fleischmann A, Bertolote JM, De Leo D, Botega N, Phillips M, Sisask M, et al. Characteristics of attempted suicides seen in emergencycare settings of general hospitals in eight low - And middle-income countries. Psychol Med 2005;35(10):1467-74.

10. Khan PA, Chary MD, Kumar MM, Nousheen BB. A study on treatment pattern and outcomes of poisoning cases in a tertiary care and government district hospital. Int J Pharm Pharm Sci 2017;9(4):193-7.

11. Vanishree R, Chavan VR, Arshad M, Raghunandan M, Faizuddin. A study on the pattern of acute poisoning in an emergency department of a tertiary care hospital. Asian J Pharm Clin Res 2016;9:361-3.

12. Singh B, Unnikrishnan B. A profile of acute poisoning at Mangalore (South India). J Clin Forensic Med 2006;13(3):112-6.

13. Ramesha KN, Rao KB, Kumar GS. Pattern and outcome of acute poisoning cases in a tertiary care hospital in Karnataka, India. Indian $\mathrm{J}$ Crit Care Med 2009;13(3):152-5.

14. Prajapati T, Prajapati K, Tandon R, Merchant S. Acute chemical and pharmaceutical poisoning cases treated in civil hospital, Ahmedabad: One year study. Asia Pac J Med Toxicol 2013;2:63-7.

15. Johnson JG, Cohen P, Gould MS, Kasen S, Brown J, Brook JS. Childhood adversities, interpersonal difficulties, and risk for suicide attempts during late adolescence and early adulthood. Arch Gen Psychiatry 2002;59(8):741-9.

16. Fetsch RJ, Collins CL, Whitney D. Preventing Youth and Adult Suicide: Fact Sheet. Colorado State University Extension; 2010. Available from: http://www.ext.colostate.edu/pubs/consumer/10213.html.

17. You S, Van Orden KA, Conner KR. Social connections and suicidal thoughts and behaviors. Psychol Addict Behav 2011;25 Suppl 1:180-4.

18. Värnik P. Suicide in the world. Int J Environ Res Public Health 2012;9(3):760-71

19. Churi S, Harsha CS, Ramesh M. Patterns of poison information queries received by a newly established South Indian poison information center. Asian J Pharm Clin Res 2012;5:79-82. 